\title{
Design and application of purified water preparation device for chemical analysis
}

\author{
Yanping $\mathrm{Li}^{1 *}$; Jianjun Fang ${ }^{1}$; Liwen $\mathrm{Hou}^{1}$ \\ ${ }^{1}$ Shandong Electric Power Technical College, Jinan, 250002
}

\begin{abstract}
Qualified purified water is essential for all chemical analysis. Spectral analysis, trace analysis and general chemical analysis require different purity of water. This paper introduces a kind of purified water preparation device which can be widely used in all chemical analysis work. The purified water preparation device consists of two-stage reverse osmosis device and water treatment device of ion exchange system. The two-stage reverse osmosis water treatment unit can be operated in two modes: program-controlled and manual mode, and the water production rate is about $80 \%$. The ion exchange water treatment unit consists of two cation exchangers, two cation exchangers and one mixed ion exchanger, which can prepare silicon free water and sodium free water and meet the requirements of trace analysis. The ion exchange water treatment unit is equipped with independent purified water pipeline system and regenerated liquid pipeline system to avoid the pollution of purified water. The regeneration operation of ion exchange resin is simple, and the discontinuous water production can be easily realized. This set of purified water preparation device can adapt to various water sources to complete purification treatment, and produce purified water meeting various chemical analysis.
\end{abstract}

\section{Overview}

A compact, efficient, and well-operated water treatment equipment is one of the infrastructure of the analysis laboratory. This water treatment equipment mainly provides all levels of water demand for analysis laboratories. The equipment uses ordinary tap water as the water source, and reverse osmosis is the predemineralization system. It is composed of a total of $3 \mathrm{RO}$ membranes in the first and second stages to separate and remove $97 \%$ of total dissolved solids. The ion exchange water treatment equipment removes residual impurities. Among them, the RO effluent can be passed through the cation exchanger and anion exchanger in turn to reach the secondary water standard for analytical laboratories, and after passing through the mixed ion exchanger, it can reach the primary water standard. In the trace analysis, the rest of the very small amount of dissolved solids by ion exchange resin to remove. Equipped with effluent conductivity and $\mathrm{pH}$ on-line instrument monitor to monitor water quality changes at any time to ensure stable and qualified water quality.

\section{Reverse osmosis (RO) water treatment system}

\subsection{RO system process}

The inlet water source of this RO system is tap water. It adopts a one-stage and two-stage arrangement, with one ultrafiltration membrane(UF), one coconut shell activated carbon filter, security filter and three RO membranes. The system process is shown in Figure 1. All operation buttons and indicators are integrated in the operation panel.

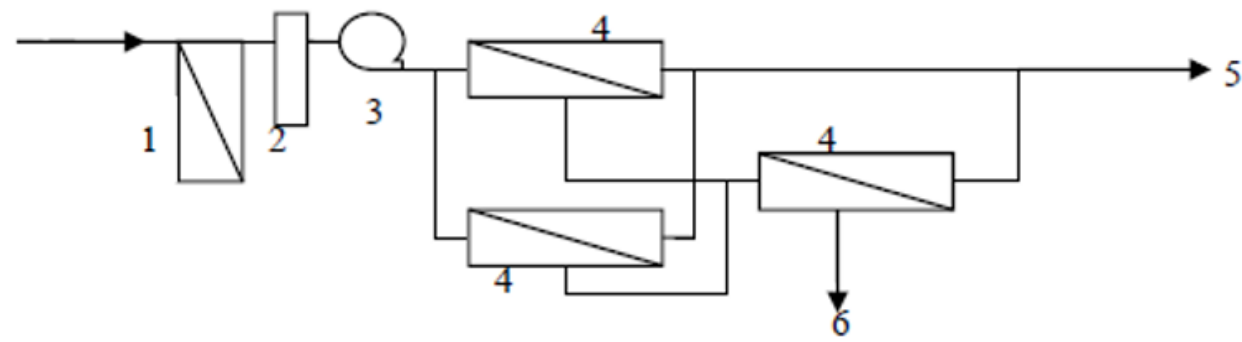

1-UF; 2-security filter; 3-high pressure pump; 4-RO; 5- product water; 6-concentrated water

Fig.1 Reverse osmosis system 


\subsection{Equipment parameters of reverse osmosis system}

RO membrane: Dow BW30-4040;

Ultrafiltration membrane: LH3-8Hd

High pressure pump: $Q=2 \mathrm{~m} 3 / \mathrm{h}, \mathrm{H}=98 \mathrm{~m}$;

Security filter: Polypropylene (PP) hot-melt filter element, filtration accuracy $5 \mu \mathrm{m}$

RO water outlet tank: $1 \mathrm{~m}^{3}$, polyethylene material, with high and low water level linkage protection.

\subsection{System settings and functions}

The outlet water tank is equipped with high water level and low water level protection equipments. The high water level protection is linked with the RO body, and it will automatically stop when the set water level is reached. The low water level protection is linked with the subsequent ion exchange system water inlet pump, and the pump is automatically stopped when the water level is lower than the set water level. Set the concentrated water return valve and pipeline to adjust the concentrated water return flow rate, water production rate, and pressure between sections. The antiscalant dosing system is started in conjunction with the high-pressure pump.

\section{3 ion exchange water treatment system}

The water inlet of the ion exchange system can switch the water source between RO outlet water and tap water as needed.

\subsection{Process of ion exchange system}

The ion exchange water treatment system consists of five ion exchange columns, including two cation exchangers, two anion exchangers and one mixed ion exchanger. It is arranged in the order of one cation exchanger + one anion exchanger + one mixed ion exchanger + one cation exchanger + one anion exchanger, as shown in Figure 2.

\subsection{Main parameters of ion exchange system}

Cation exchange resin: $001 \times 7$ Strong acid cation exchange resin for water treatment;

Anion exchange resin: $201 \times 7$ Strong basic cation exchange resin for water treatment;

Ion exchange column: $\varphi 200 \mathrm{~mm} \times 1000 \mathrm{~mm}$;

High-level water tank: $\mathrm{V}=0.25 \mathrm{~m}^{3}$;

Acid and alkali tank: $\mathrm{V}=0.05 \mathrm{~m}^{3}$;

Acid (/alkali pump): polypropylene

corrosion-resistant centrifugal pump, $\mathrm{Q}=3 \mathrm{~m}^{3} / \mathrm{h}, \mathrm{H}=6 \mathrm{~m}$; Resin mixing ratio: (positive: negative resin $=1: 2$ );

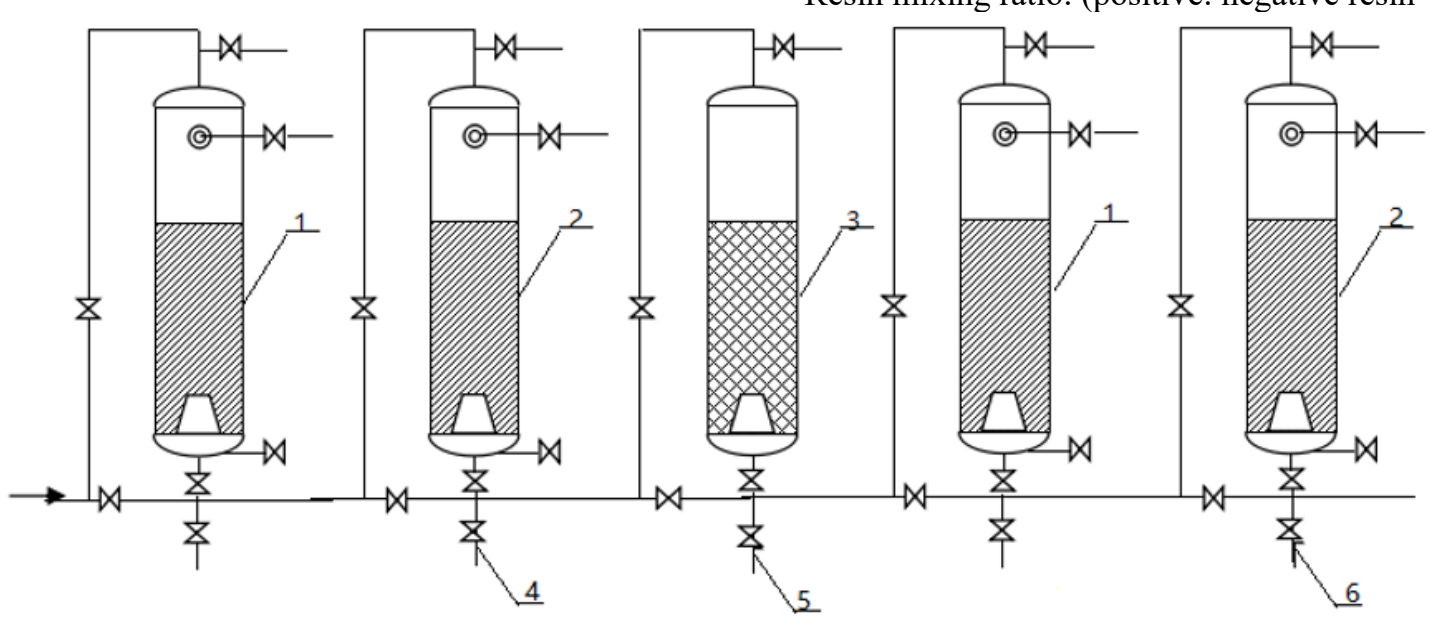

Legend: 1-Cation exchanger; 2-Cation exchanger; 3-Mixed ion exchanger; 4-level 1 outlet; 5-level 2 outlet; 6 -level 3 outlet

Fig. 2 Structure of ion exchange equipment

\subsection{Regeneration of ion exchange resin}

The regeneration system is relatively independent, adopting the design of low-position acid-base tank for liquid distribution and high-position acid-base tank for self-flow regeneration, as shown in Figure 3. The regeneration process does not require continuous operation of acid-base pumps. During the regeneration process, the regeneration liquid flows smoothly, the resin does not mess up, the regeneration degree is high, and the effluent quality is good.

\section{Application effectiveness}

\subsection{Water requirements for analytical laboratories}

According to the national standard GB/T6682-2008, laboratory water is divided into three specifications, as shown in Table 1. Among them, tertiary water is used for general chemical analysis experiments, secondary water 


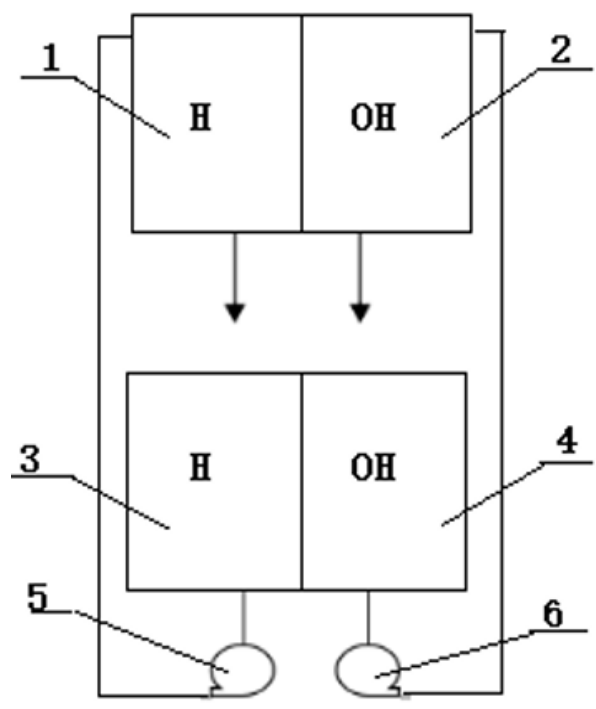

Legend: 1 - high acid tank; 2 - high alkali tank; 3 - low acid tank;4 - low alkali tank; 5-Acid pump;6-alkali pump.

Fig.3 Reborn aqua system

is used for precision chemical analysis such as inorganic trace analysis, and primary water is used for analytical

experiments with strict requirements. The water quality of the water treatment unit is shown in Table 2.

Tab.1 Water for analytical laboratory use Specification

\begin{tabular}{c|c|c|c}
\hline Test item & Level 1 & Level 2 & Level 3 \\
\hline $\mathrm{pH}\left(25^{\circ} \mathrm{C}\right)$ & - & - & $5.0 \sim 7.5$ \\
\hline Conductivity $\left(25^{\circ} \mathrm{C}\right)$ & $\leq 0.01$ & $\leq 0.10$ & $\leq 0.50$ \\
\hline Oxidable (calculated as O) $\mathrm{mS} / \mathrm{m} / \mathrm{L}$ & - & $\leq 0.08$ & $<0.40$ \\
\hline Absorbance $(254 \mathrm{~nm}, 1 \mathrm{~cm}$ optical path) & $\leq 0.001$ & $\leq 0.01$ & - \\
\hline Evaporation residue $\left(105^{\circ} \mathrm{C}\right) \mathrm{mg} / \mathrm{L}$ & - & $\leq 1.0$ & $\leq 2.0$ \\
\hline Soluble silicon (calculated as $\mathrm{SiO} 2) \mathrm{mg} / \mathrm{L}$ & $\leq 0.01$ & $\leq 0.02$ & - \\
\hline
\end{tabular}

\subsection{Water quality of water treatment plant}

Tab.2 Water quality of water treatment plant

\begin{tabular}{c|c|c}
\hline Detection location & Conductivity $\left(25^{\circ} \mathrm{C}\right) \mathrm{mS} / \mathrm{m}$ & $\mathrm{pH}\left(25^{\circ} \mathrm{C}\right)$ \\
\hline Raw water & $62 \sim 68$ & $7.49 \sim 7.56$ \\
\hline RO Produced water & $1.2 \sim 2.0$ & $6.9 \sim 7.3$ \\
\hline level 1 Outlet & $0.006 \sim 0.02$ & $6.7 \sim 6.8$ \\
\hline level 2 Outlet & $0.006 \sim 0.01$ & $6.5 \sim 6.8$ \\
\hline level 3 Outlet & $0.0056 \sim 0.01$ & $6.8 \sim 7.0$ \\
\hline
\end{tabular}

\section{Conclusion}

The purifying water treatment equipment has been used in many research institutions and university analysis laboratories. Raw water can be used tap water or other water sources, after the reverse osmosis purification treatment to remove most of the dissolved solids, and then through the ion exchange resin to remove the residual dissolved solids, appropriately increase the number of positive and negative beds, can improve the quality of water production, to meet the requirements of more precise analysis and test. This water treatment and purification device has been in use for more than 3 years. At present, the desalination rate of reverse osmosis system is stable at more than $97 \%$. The water yield of ion- exchange water treatment equipment in each operation cycle is related to the dissolved solid content of reverse osmosis produced water. Under the condition that the effluent conductivity is not higher than $1.5 \mathrm{~ms} / \mathrm{m}$, the system can produce about $500 \mathrm{~m}^{3}$ of pure water for analysis laboratory each operation cycle, and the ion exchange resin needs to be regenerated once a year. Therefore, the water treatment equipment has a high prospect of popularization and application.

\section{References}

1. H. Chengqun. Water treatment equipment and operation of power plant, China Electric Power Press, (2015)

2. G. Jiaocheng. Ion exchange membrane and its 
application in water treatment[J]. Science and Technology Information, 12(31):44(2014)

3. M. Shuqiang. Comparison of water treatment with full membrane method and ion exchange desalination system[J]. Journal of Chongqing Electric Power College, 17(02): 85-87(2012)

4. Z. Xiaoping. Wen Quan, Xu Bin. Application of ion exchange real bed in the preparation of pure water[J]. Guangdong Chemical Industry, 44(11): 172174(2017)

5. L.Yanping $\mathrm{i}$,An ion exchange water treatment training device for teaching[P].Chinese patent,20180907

6. Yanping $\mathrm{Li}, \mathrm{An}$ ion exchange resin treatment device[P].Chinese patent, 20200619

7. Water for analytical laboratory use Specification and test methods, GB/T6682-2008 (IOS 3696:1987, MOD) 